\title{
Hypothetical Comparison in Turkish
}

\author{
Utku Türk \& Ömer Demirok*
}

Abstract. In this paper, we present a preliminary investigation of the complex formative -MIŞCASINA in Turkish, used for hypothetical comparison. We observe that -MIŞCASINA differs from its counterparts in previously studied hypothetical comparison constructions in one key aspect: it can naturally target non-eventive nominal predicates. Furthermore, we find that -MIŞCASINA is primarily licensed in linguistic contexts that make a gradable property available. Building on these initial empirical observations, we flesh out a novel account of hypothetical comparison that makes use of a well-established formalism of degree semantics and semantics of equatives, without invoking the notion of event similarity which is central to previous accounts. In particular, we argue that -MIŞCASINA compares an actual degree against hypothetical degrees, asserting that the actual degree is greater than or equal to any of the hypothetical degrees.

Keywords. hypothetical comparison, equatives, degree semantics, Turkish

1. Introduction. This paper presents a preliminary semantic analysis for the internally complex formative -MIŞCASINA in Turkish which functions as a hypothetical comparison marker, as shown in (1). ${ }^{1,2}$ We set aside its internal complexity and gloss it as HCM. ${ }^{3}$

$\begin{array}{llllll}\text { (1) Can arka-sın-dan } & \text { biri } & \text { koval-1yor-muşcasına } & \text { hizl1 yürü-dü. } \\ \text { Can } & \text { behind-POSS.3SG } & \text { somebody } & \text { chase-IMPF]-HCM } & \text { fast } & \text { walk-PST }\end{array}$

Lit: 'Can walked fast as if [somebody was chasing him].'

Previous research on hypothetical comparative markers (also referred as comparative complementizers) is very limited with respect to the cross-linguistic typology. To the best of our knowledge, existing research on this topic only covers American English (Bledin \& Srinivas 2019), Canadian English (Brook 2014), and German (Bücking 2017). Consequently, the analyses provided in the literature only address the empirical observations made for hypothetical comparison constructions in these languages. All available semantic analyses of hypothetical comparison make use of event semantics and invoke the notion of event similarity (Umbach \& Gust 2014). Consider the following example from Bledin \& Srinivas (2019) and the paraphrase they provide for it, which should suffice to illustrate the type of analysis they argue for.

a. Pedro danced as if he was possessed by the demons part that contributes hypothetical comparison

\footnotetext{
*We thank Furkan Atmaca, Elena Guerzoni, and Deniz Özyıldız for their comments and contributions in the early forms of this work. We would also like to thank the anonymous reviewers on Tu+6. Authors: Utku Türk, Boğaziçi University (utku.turk@boun.edu.tr) \& Ömer Demirok, Boğaziçi University (omerfaruk.demirok@boun.edu.tr).

${ }^{1}$ Abbreviations: $1=$ first person, $2=$ second person, $3=$ third person, $\mathrm{ABL}=$ ablative, $\mathrm{ACC}=$ accusative, $\mathrm{DAT}=$ dative, $\mathrm{FUT}=$ future, $\mathrm{HCM}=$ hypothetical comparative marker, $\mathrm{IMPF}=$ imperfective, $\mathrm{LOC}=$ locative, $\mathrm{NEG}=$ negative, $\mathrm{PL}=$ plural, POSS $=$ possessive, $\mathrm{PST}=$ past, $\mathrm{SG}=$ singular.

${ }^{2}$ We use Turkish orthography throughout the paper, some of which do not match with proper IPA symbols. The following are their IPA counterparts. ü: [y], ö: [ø], 1: [u], ç: [t]], c: [б]], ş: [j]. In addition, we use bold face to signal HCM component and box to show the gradable element.

${ }^{3}$ It seems that -MIŞCASINA can be decomposed into four different morphemes: the evidential suffix -MIŞ, the derivational suffix -CA, possessive suffix -SIN, and allative/dative suffix -A. Notably, many speakers report that the -MIŞ part of HCM is omissible without any change in meaning.
} 


\section{b. $\approx$ Pedro's actual dancing resembles his dancing in the closest possible situations where he was possessed by demons.}

Even though the meaning contribution of -MIŞCASINA is similar to the contribution of as if in English and wie wenn in German, we pursue a new approach in analyzing HCM in Turkish. We propose that HCM compares degrees, without invoking the notion of event similarity. In particular, we propose that a more transparent paraphrase for the Turkish sentence in (1) is (3), which makes it evident that sentences with HCM involve degree comparison.

(3) Can walked as fast as he would (walk) if somebody were chasing him.

We motivate our departure from an analysis that invokes the notion of event similarity based on the observation that HCM in Turkish is compatible with non-verbal predicates (but crucially those that denote gradable properties). An example HCM attaching to a non-verbal predicate is in given below in (4).

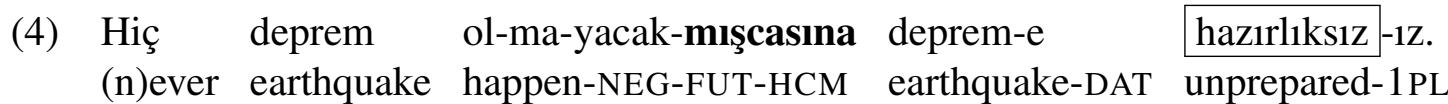

Lit: 'We are unprepared for an earthquake as if there is never gonna be one.'

It is not clear to us whether the notion of event similarity is compatible with non-verbal predicates. However, the compatibility of HCM with non-verbal predicates that denote gradable properties is expected under our proposal that the semantics of HCM in Turkish involves degree comparison. ${ }^{4}$ Although we do not make any claims regarding what the facts are in English or German, it seems that the hypothetical comparison constructions in these languages do not readily accept non-verbal predicates, as the empirical descriptions provided in the papers cited above suggest. ${ }^{5}$

Thus, in this paper, we delve into an undocumented corner of Turkish grammar, describing where HCM is licensed and what it contributes when it is licensed, and furthermore provide a novel semantic analysis that seems to best fit the data at hand. We hope that this paper helps document the cross-linguistic typology of hypothetical comparison constructions and the logical space of possible semantic analyses for such constructions.

The paper is structured as follows. After providing our initial observations in the next section, we provide our proposal in section 3 and a compositional implementation in section 4 . In section 5 , we briefly discuss some further empirical questions, proposing certain refinements in the analysis. In section 6, we discuss data that constitute an important challenge for a uniform treatment of HCM in Turkish. Section 7 concludes the paper.

2. Describing HCM in Turkish. Sentences that feature HCM, typically, contain an element denoting a gradable property. The gradable element can be an adjectival predicate as in (5), or an adverbial modifier to the main event as in (6).

\footnotetext{
${ }^{4} \mathrm{An}$ anonymous reviewer asks if the notion of event similarity can be generalized to non-verbal predicates. We do not yet have a sufficiently informed opinion on this issue. We should note, however, that there is no explicit discussion of this question in the relevant works.

${ }^{5}$ For further comments on how English might be different from Turkish in this respect, see section 6 where we point to some observations based on our informal elicitation from native speakers of English.
} 
(5) Helin pandemi bit-mişcesine mutlu.

Helin pandemic end-HCM happy.3SG

Lit: 'Helin is happy as if the pandemic is over.'

(6)

$\begin{array}{lllll}\text { Hasan } & \text { boğaz-1 } & \text { acı-1yor-muşcasına } & \text { sessiz } & \text { konuş-uyor-du. } \\ \text { Hasan } & \text { throat-POSS.3sG } & \text { hurt-IMPF-HCM } & \text { quiet(ly) } & \text { speak-IMPF-PST }\end{array}$

Lit: 'Hasan was speaking quietly as if his throat hurts.'

Given sentences like (5) and (6), a hypothesis with initial plausibility is that the HCM-clause (i.e. the constituent whose predicate HCM is suffixed to) is in a direct syntactic modification relationship with the element that denotes a gradable property. For example, the HCM-clause in (6) might appear to be modifying sessiz, specifying its degree. Similarly, it does seem like (5) may have the simplified constituent structure depicted in (7).

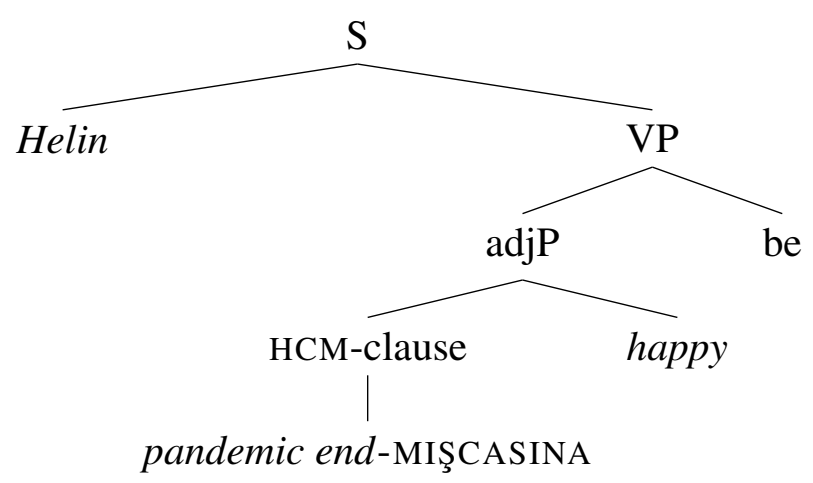

We argue that the direct modification relationship of the kind illustrated above cannot be the right analysis of how HCM-clauses are integrated into sentences. There is empirical evidence that HCM-clauses are not syntactic adjuncts of these gradable elements; rather, they are sentential modifiers. ${ }^{6}$ For example, when we try to force an HCM-clause into a DP, sandwiching it between a demonstrative and a gradable adjective, the result is an unacceptable sentence, as illustrated in (8).

(8) * Şu [Tolstoy yaz-mışcasina uzun] roman-1 uzat lütfen! That [Tolstoy write-HCM long] novel-ACC pass.IMP please Intended: 'Pass me that long book which looks like Tolstoy wrote it!'

This unacceptable sentence could only have a structure as in (9) where the HCM-clause is a syntactic modifier of the adjective uzun 'long'. Given the ungrammaticality of the sentence, we conclude that HCM-clauses do not directly modify adjectives or adverbs that denote gradable properties.

\footnotetext{
${ }^{6} \mathrm{An}$ anonymous reviewer wonders if there is positive evidence for the sentential modifier status of HCM constructions. As far as we can see, their status as sentential modifiers can only be shown by providing evidence against alternative attachment possibilities, as we do here.
} 
(9)

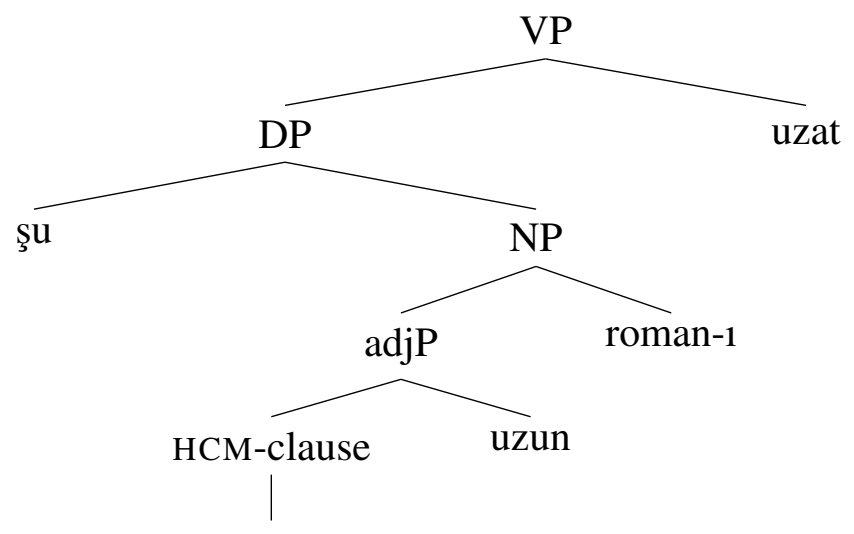

Tolstoy yaz-mışcasına

We should note that there are similar complex modifiers that can occur in this position, modifying an adjective as in (10). We only argue that a HCM-clause is not one of them.

$\begin{array}{lllllll}\text { (10) } & \text { Şu } & \text { [Tolstoy-un-ki-ler } & \text { kadar } & \text { uzun } & \text { roman-1 } & \text { uzat lütfen! } \\ \text { That } & \text { [Tolstoy-GEN-REL-PL } & \text { AS-MUCH-AS } & \text { long] } & \text { novel-ACC } & \text { pass.IMP please }\end{array}$ $\approx$ 'Pass me that book which is as long as Tolstoy's (novels)!'

We argue that HCM-clauses can modify a sentence as long as it contains a gradable element, regardless of what its category might be. Our previous examples included an adverbial in (1) and (6), a denominal adjective in (4), a simplex adjective in (5). We show below that a sentence containing a deverbal adjective as in (11) is equally a licit base for the HCM-clause.

(11) Hiç destek al-ma-mışcasına y1kık bir hal-de-ydi.

n(ever) support receive-NEG-HCM destroyed a condition-LOC-PST

Lit: 'They (sg.) were devastated as if they never had help.'

What HCM-clauses require is that these adjectives or adverbs denote gradable properties. Following Kennedy \& McNally (2005), we observe that HCM-clauses only combine with sentences containing elements with an open scale. Indeed, an HCM-clause fails to modify sentences containing elements with a closed scale, in other words non-gradable or absolutive elements. Consider (12) where we have absolutive adjective yanlış, meaning 'wrong.' Given previous examples, one might expect that the sentence should not create any problem as it does contain an adjective. However, the utterance is ungrammatical. This ungrammaticality also extends to other absolutive elements such as adjective like 'golden' or 'full.'7

$$
\begin{array}{llll}
\text { \# Cevab-1 } & \text { soru-yu } & \text { duy-ma-mışcasına } & \text { yanlış-t1. } \\
\text { answer-POSS-3SG } & \text { question-ACC } & \text { hear-NEG-HCM } & \text { wrong-PST }
\end{array}
$$

Lit: 'His answer was wrong as if he did not hear the question.'

Taken together, we conclude that HCM-clauses in Turkish are modifiers that can combine with sentences containing gradable elements. Accordingly, we take them to denote functions from degrees to propositions, as will be discussed.

\footnotetext{
${ }^{7}$ It may be possible to coerce some non-gradable predicates into gradable construals, which may then improve the acceptability of HCM construction with such predicates. We set aside this possibility in this paper.
} 
3. Proposal. The analysis that we would like to pursue for HCM involves degree comparison. Intuitively, the kind of degree comparison HCM makes is akin to the kind of degree comparison we see in equatives. This is best understood by considering again the paraphase in (14) for the sentence in (1), repeated below in (13).

Can [arka-sın-dan $\quad$ biri $\quad$ koval-1yor]-muşcasına
Can hılı yürü-dü.
Lit: 'Can walked fast as if [somebody was chasing him].'
Can walked as fast as he would walk if somebody was chasing him.

Given the paraphrase in (14), HCM seems to be comparing an actual degree against degrees in hypothetical worlds. The sentence in (13), when true, entails there is an actual event of Can walking, which takes place at some degree $d$ of fastness, which is our actual degree. What HCM does is compare this actual degree $d$ against possible degrees of fastness $d^{\prime}$ in hypothetical worlds where Can walks. The clause whose predicate HCM is attached to is a proposition (a set of worlds) which tell us which hypothetical worlds we are talking about. In (13), these hypothetical worlds are worlds in which somebody is chasing Can. Thus, HCM compares a degree in the actual world against degrees from possible worlds which the HCM-clause points to.

Given this intuitive paraphrase, we propose the informal truth conditions for (13) in (15). This will be made formally precise in the next section and further refined in section 5 .

(15) Truth conditions for (13) (to be made more precise):

The degree of speed $d$ at which Can walked in the actual world is greater than or equal to any degree of speed $d^{\prime}$ at which Can would be walking in hypothetical worlds where somebody is chasing him.

Notice that the truth conditions that the sentence delivers does not tell us how fast Can walked in the actual world. But it does tell us that it was as fast as he would walk if he were chased by somebody. Reasoning through our world knowledge, we can easily deduce that Can walked pretty fast.

4. A compositional implementation. Although there are other logical forms that can derive the truth conditions we have proposed in the previous section, we take the simplest possible compositional route and assume that HCM is a 2-place function, gathering all the compositional pieces and outputs the target truth conditions.

The first argument of the function that HCM denotes is a proposition of type $\langle s, t\rangle$. This proposition will tell the function which hypothetical worlds to look into to do the comparison. The second argument of the function that HCM denotes is a function from degrees to propositions. We believe that this compositional analysis also faithfully reflects the sentential adjunction of HCM-clauses. Hence, the simplified logical form for the sentence in (13) will be as in (16) ${ }^{8}$ Below, we discuss how we derive the meaning of the second argument of the function that HCM denotes.

\footnotetext{
${ }^{8} \mathrm{We}$ ignore tense throughout. We leave its integration into the compositional derivation to future research.
} 
(16)

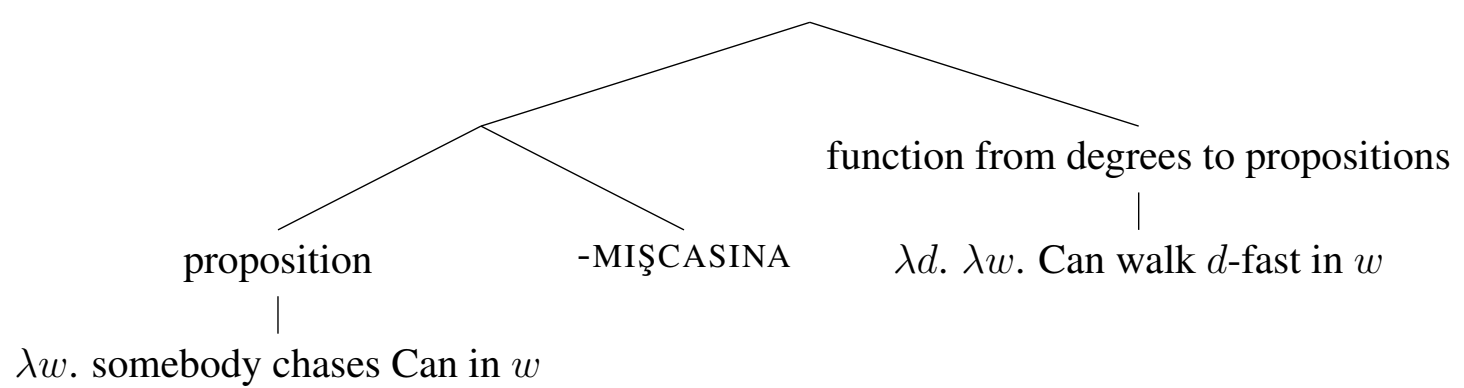

We assume that the function from degrees to propositions is derived by $\lambda$-abstracting over the degree variable of the gradable property in the main clause. Syntactically speaking, this can be construed as a kind of relativization operation if $\lambda$-abstraction is exclusively an effect of movement (Heim \& Kratzer 1998). But nothing hinges on this syntactic assumption.

Furthermore, to represent intensionality, we follow the Split Intensionality theory in Keshet (2010). Accordingly, the operator $\wedge$ that abstracts over the world parameter, defined in (17), is inserted in the structure when composition requires intensions.

$$
\llbracket \wedge \alpha \rrbracket^{\mathrm{w}}=\lambda w^{\prime} \cdot \llbracket \alpha \rrbracket^{\mathrm{w}^{\prime}}
$$

The unpacked logical form that incorporates these proposals is shown below (18).

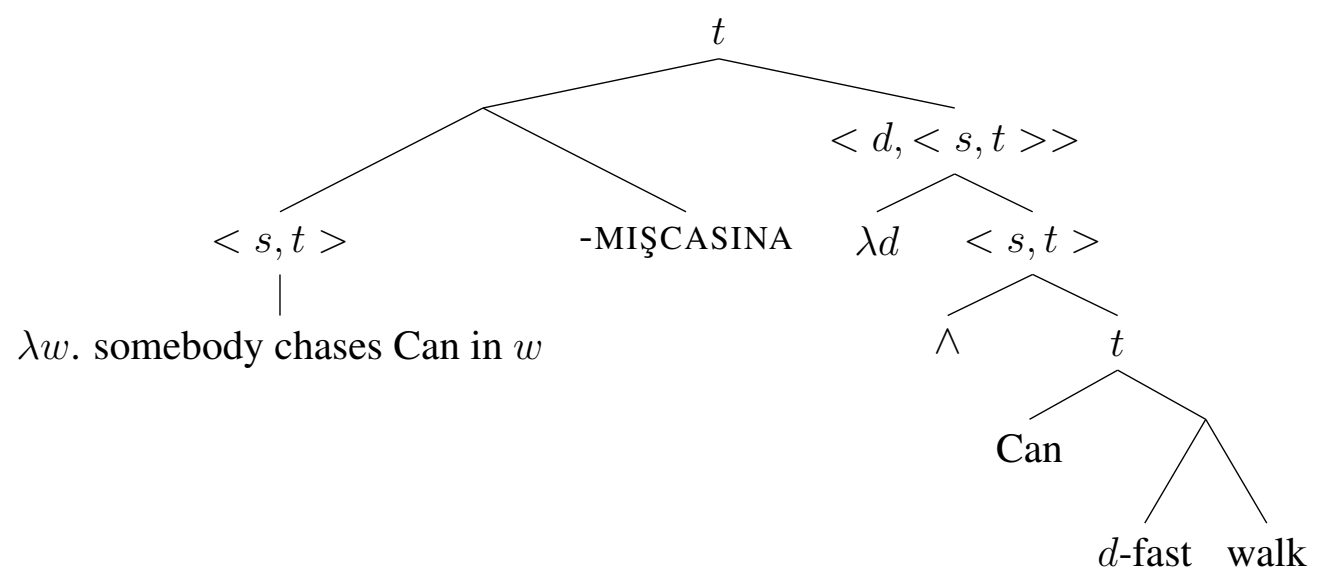

The function that will output the desired truth conditions within this logical form is the 2-place function given in (19), which we take to be what HCM means.

$$
\begin{aligned}
& \llbracket \text {-MIŞCASINA } \rrbracket^{w}=\lambda p_{<s, t>} \lambda Q_{<d, s t>} \cdot \forall w^{\prime}: p\left(w^{\prime}\right) \rightarrow \text { the max } d \text { such that } Q(d)(w)=1 \\
& \geqslant \text { the max } d^{\prime} \text { such that } Q\left(d^{\prime}\right)\left(w^{\prime}\right)=1 \quad \text { (to be revised slightly) }
\end{aligned}
$$

Plugging in the given meaning of HCM in (18) derives the target truth conditions, as shown below.
a. $\llbracket(18) \rrbracket^{w}$ $=1$ iff
b. 【-MIŞCASINA $\rrbracket^{w}\left(\lambda w^{\prime}\right.$. somebody chases Can in $\left.w^{\prime}\right)\left(\lambda d^{\prime} . \lambda w^{\prime}\right.$. Can walk $d^{\prime}$-fast in $\left.w^{\prime}\right)$ $=1$ iff 
c. $\left[\lambda Q_{<d, s t>} \cdot \forall w^{\prime}\right.$ : somebody chases Can in $w^{\prime} \rightarrow$ the max $d$ such that $Q(d)(w)=1 \geqslant$ the max $d^{\prime}$ such that $\left.Q\left(d^{\prime}\right)\left(w^{\prime}\right)=1\right](\lambda d . \lambda w$. Can walk $d$-fast in $w)$ $=1$ iff

d. $\forall w^{\prime}$ : somebody chases Can in $w^{\prime} \rightarrow$ the max $d$ such that Can walk $d$-fast in $w \geqslant$ the max $d^{\prime}$ such that Can walk $d^{\prime}$-fast in $w^{\prime}$.

e. in words:

for any world $w^{\prime}$ where somebody chases Can in $w^{\prime}$, the maximal degree $d$ such that Can walks $d$-fast in the actual world is greater than or equal to the maximal degree $d^{\prime}$ such that Can walks $d^{\prime}$-fast in $w^{\prime}$

Notice that in the calculation, the second argument of the function that HCM denotes is used 'twice', so to speak, to retrieve the maximal degree in the actual world and also to retrieve the maximal degrees in the comparison set (i.e. the relevant hypothetical worlds). This is possible thanks to the fact that HCM, in essence, acts as an intensional operator that can plug into its second argument the evaluation world as well any world that is provided by its prejacent proposition in its sister.

Finally, it should be noted that in this analysis sketched above, we make use of an independently justified semantics for equative constructions which is based on a now-standard semantics of degrees. See in particular Rett (2020), Schwarzschild (2008), Bhatt \& Takahashi (2007), Heim (2000), and Stechow (1984). However, the use of degree semantics in the context of hypothetical comparison is our novel contribution, to the best of our knowledge.

5. Some further issues and refinements. In this section, we consider some further questions and observations and provide some refinements. In section 5.1, we show that our analysis correctly predicts that HCM is not able to co-occur with other degree constructions. In section 5.2, we discuss which possible worlds should be considered for the comparison, integrating stereotypicality into the meaning of HCM. Next, we turn to the standard of comparison in section 5.3. Finally, in section 5.4, we touch upon the issue of counterfactuality.

5.1 Already Bound Degree Variable. We have seen that our analysis correctly rules out cases where the sentence that the HCM-clause modifies has no suitable gradable element, as was shown in (12). There is a related prediction that our analysis makes. We predict that when there is a gradable expression whose degree variable is already bound, HCM will not be licensed. Indeed, when degree variables are bound by other operators such as superlative or comparative as in (21b) and (21c), HCM structures are infelicitous.

$$
\begin{array}{llll}
\text { a. Mecidiyeköy } & \text { cehennem-mişcesine } & \text { kalabalık bir ilçe-miz-dır. } \\
\text { M } & \text { hell-HCM } & \text { crowded a district-POSS.1 PL-PST. }
\end{array}
$$

Lit: 'Mecidiyeköy is an crowded district as if it was hell.'

Our paraphrase $=$ 'Mecidiyeköy is as crowded a district as it would be if it were hell.'

b. * Mecidiyeköy cehennem-mişcesine en kalabalık ilçe-miz-dır. M hell-HCM most crowded district-POSS.1 PL-PST.

Intended: 'Mecidiyeköy is the most crowded district as if it was hell.' 


\section{c. * Mecidiyeköy cehennem-mişcesine Kadıköy-den daha M hell-HCM K-ABL more \\ kalabalık bir ilçe-miz-dır. \\ crowded a district-POSS.1PL-PST.}

Intended: 'Mecidiyeköy is more crowded a district than Kadıköy as if it was hell.'

This set of data is correctly ruled out under our analysis, for the function that HCM denotes takes as its second argument as function from degrees to propositions. Recall that we derive this function by $\lambda$-abstraction. When the degree variable is already used up by another operator such as comparative or superlative, $\lambda$-abstraction simply cannot apply, leaving HCM without its second argument. In short, (21b) and (21c) are ruled out as type mismatches.

5.2 Limiting Possible Worlds. An obvious problematic aspect of the meaning we gave to HCM is the fact that it takes a set of worlds and asserts that comparison goes through for each world in that set. See the meaning below.

$$
\begin{aligned}
& \llbracket \text {-MIŞCASINA } \rrbracket^{w}=\lambda p_{<s, t>} \cdot \lambda Q_{<d, s t>} \cdot \forall w^{\prime}: p\left(w^{\prime}\right) \rightarrow \text { the max } d \text { such that } Q(d)(w)=1 \\
& \geqslant \text { the max } d^{\prime} \text { such that } Q\left(d^{\prime}\right)\left(w^{\prime}\right)=1
\end{aligned}
$$

It is clear that not all possible worlds where the propositional argument is true should be included in this comparison. Consider (23) again.

$\begin{array}{llllll}\text { Can arka-sın-dan } & \text { biri } & \text { koval-1yor-muşcasına } & \text { hızlı } & \text { yürü-dü. } \\ \text { Can behind-POSS.3SG } & \text { somebody } & \begin{array}{l}\text { chase-IMPF-HCM } \\ \text { fast }\end{array} \text { walk-PST } \\ \text { Lit: 'Can walked fast as if somebody was chasing him.' } & & \end{array}$

Intuitively, we feel that the comparison set in this sentence contains worlds where Can speeds up when somebody chases him. But suppose there is some crazy possible world $\mathrm{w}_{299792458}$ where Can walks at the speed of light when somebody chases him (setting aside the question if that can still be called a walking event). If $\mathrm{w}_{299792458}$ is in the comparison set, given the universal quantification that HCM brings in, the truth conditions predict that Can's actual speed of walking is as fast as his speed in $\mathrm{w}_{299792458 .}{ }^{9}$ Yet it is clear that to judge (23) as true, we certainly do not feel the need to submit that Can walked at a nonhuman speed. In short, it seems clear that the set of worlds that enter the comparison set are possible worlds that are most similar to ours, the actual world.

To restrict the possible worlds HCM looks at, we follow the steps of Bledin \& Srinivas (2019) and utilize Kratzerian ordering sources (Kratzer 1981 1991), setting aside the details of its implementation. Using this approach, Bledin \& Srinivas (2019) order worlds from the least stereotypical to the most stereotypical and select only the most stereotypical worlds. See (24a) for their proposal and (24b) for our updated truth conditions for (23).

a. Stereotypicality relation between worlds

$v \leq_{w} u$ iff $v$ is at least as typical as $u$ from the perspective of $w$

b. $\llbracket 23 \rrbracket^{w}=1$ iff for any world $w^{\prime}$ most stereotypically similar to $w$ such that somebody chases Can in $w^{\prime}$, the maximal degree $d$ such that Can walks $d$-fast in $w \geqslant$ the maximal degree $d^{\prime}$ such that Can walks $d^{\prime}$-fast in $w^{\prime}$.

\footnotetext{
${ }^{9}$ An anonymous reviewer asks if we take the scale of speed as an open scale yet bound by the speed of light. Although nothing hinges on this for the current example, let us assume that language ignore these types of bounds.
} 
This adjustment correctly predicts that anyone that hears (23) would understand that Can walked faster than usual, given that the stereotypical response to being chased is running away.

A related question is what happens when Can himself is a non-stereotypical person. Suppose anyone who knows Can knows that, for whatever reason, Can's reaction to being chased is freezing, i.e. not running away or speeding up. Our analysis correctly predicts that the sentence in (23) is odd if used by people who know Can addressing people who know Can. While it is true that people stereotypically speed up/run away if they are chased by someone, Can is not such a person. The comparison set $\{\mathrm{w}$ : $\mathrm{w}$ is most stereotypically similar to the actual world such that somebody chases Can in w $\}$ will likely only contain worlds where Can doesn't move at all. So, in this context, we predict that (23) is not informative in that any degree of speed satisfies the condition of being greater than or equal to zero speed.

5.3 STANDARD OF COMPARISON. An anonymous reviewer points out that the adverb "hızlı" in examples like (25) may be doing more than providing a scale of fastness. In particular, it also seems to contribute a positive degree, meaning that (25) entails that Ali walked fast according to a standard point of comparison (e.g. standard human pace in walking). We are able to infer that the adverb does indeed contribute a positive degree, based on the observation that a sentence like (25) sounds ironic or funny to many speakers. The reason for that is that the sentence entails both that Ali walked fast (according to standard human pace in walking) and that Ali's pace was greater than or equal to his pace in possible worlds where a snail is chasing him. In these informally stated truth conditions, when the first conjunct is true, the second conjunct is trivially true. We hypothesize that the triviality here is accommodated, leading many speakers to report that this sentence is an ironic way to say Ali walked really slowly.

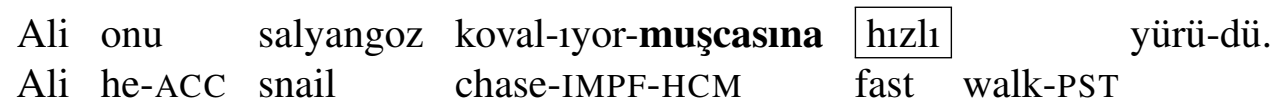

Intended: 'Ali walked as fast as he would walk if a snail was chasing him.'

If the way we think about this sentence is on the right track, our analysis needs to be modified slightly to capture the additional inference concerning the positive use of the gradable element. There is nothing in the meaning of НCM (and the truth conditions that we derive) about the contribution of a positive degree. But we can easily make it part of the meaning of HCM, by adding a contextual standard $\mathbf{s}$ against with the actual maximal degree is compared. This is a common way of analyzing positive use of adjectives. For relevant discussion, we refer the reader to Kennedy \& McNally (2005).

$$
\begin{aligned}
& \llbracket \text {-MIŞCASINA } \rrbracket^{w}=\lambda p_{<s, t>} \cdot \lambda Q_{<d, s t>} \cdot \forall w^{\prime}: p\left(w^{\prime}\right) \rightarrow \text { the max } d \text { such that } Q(d)(w)=1 \\
& \geqslant \text { the max } d^{\prime} \text { such that } Q\left(d^{\prime}\right)\left(w^{\prime}\right)=1 \& \text { the max } d \text { such that } Q(d)(w)=1>\mathbf{s}
\end{aligned}
$$

5.4 Counterfactuality. One final issue that we need to address concerns the counterfactuality inferences that some speakers associate with HCM clauses. It appears that a sentence like (4), repeated here as (27), gives rise to an inference that the HCM-clause is false in the actual world.

Hiç deprem ol-ma-yacak-mışcasına deprem-e hazırlıksız-1z. (n)ever earthquake happen-NEG-FUT-HCM earthquake-DAT unprepared-1PL

Lit: 'We are unprepared for an earthquake as if there is never gonna be one.' $\rightsquigarrow$ There is going to be an earthquake. 
One way to formally integrate this inference to our entry for HCM is to hypothesize that prejacent proposition is presupposed to be false in the actual world. If this hypothesis were to be true, we would predict that a speaker may utter a sentence of the form ' $p$-MIŞCASINA $q$ ' only if she believes that $\mathrm{p}$ is false in the actual world. However, this is an incorrect prediction as a sentence like (28) is felicitious in a context of ignorance. "But, I do not know if he had any help," is a perfectly fine continuation of (28).

$$
\begin{array}{llllll}
\text { Ali } & \text { destek } & \text { al-ma-mışcasına } & \text { y1k1k } & \text { bir } & \text { hal-de-ydi. } \\
\text { Ali } & \text { support } & \text { receive-NEG-HCM } & \text { devastated a } & \text { situation-LOC-PST }
\end{array}
$$

Lit: 'Ali was devastated as if he never had help.'

It is, however, possible that HCM imposes a weaker requirement that the speaker has no belief that $\mathrm{p}$ is true if they are uttering a sentence of the form ' $p$-MIŞCASINA $q$ ' ${ }^{10}$ It seems to us that this weaker requirement is correct. For example, it is very difficult to imagine someone uttering (29): it does sound contradictory. That said, we subject that this matter requires further investigation.

(29) Ali hiç destek almadı. Tam olarak da bu sebeple (\#hiç destek almamışcasına) yıkık bir haldeydi.

Ali never got help. That's exactly why he was devastated (\#as if he never had any help).

6. A challenge for a uniform account. In section 2, we mentioned that sentences that employ HCM for hypothetical comparison typically contain an element denoting a gradable property. However, this is not always the case. An important challenge for our proposal that HCM compares degrees is that there are sentences like in in (30), where there is no overt gradable element that HCM can work with.
Yarın sinav-1n
yok-muşcasına otur-uyor-sun!
tomorrow exam-POSS.2SG
exist.NEG-HCM sit-IMPF-2SG
Lit: 'You are sitting as if you didn't have an exam tomorrow.'

An easy way out of this problem that also preserves a uniform semantic analysis is, obviously, to posit a covert adverb. It could be the case that we retrieve a plausible adverb from the context in sentences like (30) and end up with an interpretation as in (31).

$\begin{array}{lllll}\text { Yarın } & \text { sınav-1n } & \text { yok-muscasına } & \text { rahat } & \text { otur-uyor-sun! } \\ \text { tomorrow } & \text { exam-POSS.2SG } & \text { exist.NEG-HCM } & \text { relaxed } & \text { sit-IMPF-2SG }\end{array}$
'You are sitting [as relaxed as you would be sitting] if you didn't have an exam tomorrow.'

This covert adverb analysis could also be employed to explain the oddness of sentences like (32). In this sentence, there are no easily conceivable adverbs that either our world knowledge or context allow us to retrieve. Then, it seems plausible to attribute the oddness of the sentence to the (possibly never-ending) search for a suitable adverb that describes how one would dance if there were gonna be a meteor shower the next day. An addressee might as well be interpreting the sentence assuming that there is indeed such an adverb but cannot be sure what it is, as indicated by [???] in the free translation.

\footnotetext{
${ }^{10}$ The weaker requirement, however it is to be formalized, is intended to be compatible with the speaker being agnostic or believing that $\mathrm{p}$ is false.
} 


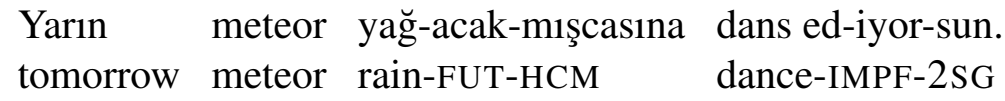

'You are dancing as [???] as you would be if there were going to be a meteor shower tomorrow.'

However, there are also problematic cases where there does not seem to be any adverb that could be posited. An example of these cases is given in (33a). Notably, some speakers disprefer such sentences and prefer to use another hypothetical comparison construction, exemplified in $(33 b)$.
a. \% Cemre ev-i
yok-muşcasına orman-da yaş [a]-1yor
Cemre house-POSs.2SG
exist.NEG-HCM forest-LOC live-IMPF
Lit: 'Cemre lives in a forest as if she doesn't have a home.'
b. Cemre ev-i yok-muş gibi orman-da yaş[a]-1yor
Cemre house-POSS.2SG exist.NEG-EVID like forest-LOC live-IMPF
Lit: 'Cemre lives in a forest like she doesn't have a home.'

It seems clear that (33a) is a case that goes against our hypothesis that -MIŞCASINA compares degrees. Notably, native speakers who accept (33a) do not report any particular oddness associated with it. Although such cases appear to be subject to speaker variability, they remain as a core challenge for a unified treatment of -MIŞCASINA. In what follows, we would like to entertain the hypothesis that at least for a subset of Turkish speakers, HCM may have an additional distinct interpretation. To situate our discussion in context, we briefly turn to English as if comparatives below, discussed in Bledin \& Srinivas (2019).

While hypothetical comparatives with non-verbal predicates are fully productive in Turkish, there does not seem to be any discussion of them in other languages. While we do not take issue with the judgments or the analysis in Bledin \& Srinivas (2019), we would like to point out that the facts they provide do not seem to be complete. Through informal consultation with English native speakers, we have found that hypothetical comparatives in English seem to be only marginally acceptable with non-verbal predicates. Consider the following example (34a), which seems to be degraded. However, there are speakers who find it acceptable with a pause, as indicated in (34b).

a. The bananas were fresh as if they'd been recently picked.

b. The bananas were fresh $\mid$ as if they'd been recently picked.

A reasonable hypothesis is that the site of adjunction of as if (and presumably its semantics) is different in (34a) and (34b). Importantly, this difference can also be detected with verbal predicates. We agree with Bledin \& Srinivas (2019) that (35a) repeated from (2a) may mean Pedro was dancing wildly — as a comment on the manner of dancing. However, (35b) with a pause has a different reading. The sentence states the fact that Pedro did dance, and apparently adds: it was surprising that he did. In other words, (35b) does not comment on the manner of dancing. Rather, it seems to be saying that what could possibly explain the fact that Pedro danced is that he was possessed. Hence, it sounds more like an answer to the question of why Pedro danced rather than how he danced.

a. Pedro danced as if he was possessed by the demons. 
b. Pedro danced $\mid$ as if he was possessed by the demons.

Given this intriguing ambiguity, it seems plausible that just like as if in English, -MIŞCASINA in Turkish may also be ambiguous for some speakers. Recall that data like (33a) constitute a challenge for the degree-based analysis we have proposed. Indeed, it appears that the interpretation of a sentence like (33a) is parallel to the interpretation of a sentence like (35b) containing a pause. Roughly, 'p-MIŞCASINA q' in (33a) and ' $\mathrm{q} \mid$ as if p' in (35b) both seem to be construed along the lines of what could possibly explain that $q$ is true is that $p$ is true (along with the aforementioned implicature that $\mathrm{p}$ is false).

If such an ambiguity is real in Turkish at least for a subset of speakers, we predict that speakers that permit ambiguity can actually interpret a sentence like (36) in two distinct ways. Under one reading, the HCM-clause comments on how fast Can walked - this is the reading captured under the degree-based analysis we have developed. Under the other reading, the HCM-clause would be construed as a (hypothetical) explanation for the fact that Can walked at the speed he walked at.

$$
\begin{aligned}
& \text { Can [arka-sın-dan biri koval-1yor]-muşcasına hızl yürü-dü. } \\
& \text { Can [behind-POSS.3SG somebody chase-IMPF]-HCM fast walk-PST } \\
& \text { Lit: 'Can walked fast as if [somebody was chasing him].' }
\end{aligned}
$$

These two readings may generally be difficult to distinguish in many cases. However, there are cases where a degree-based semantics for HCM fails to derive a licit interpretation, as we have discussed. One such example which contains a non-gradable adjective is in (37). For speakers who have the ambiguity we have sketched, this sentence should have an interpretation that survives. Under this surviving interpretation, we would expect the proposition 'he didn't hear the question' to be construed as a hypothetical explanation for the fact his answer was wrong. In other words, speakers who do not avoid (33a) should not outright reject (37), either. We have not been able to find a large enough sample of speakers who accept (33a) to verify this prediction. But our preliminary findings suggest this prediction may be right.

$$
\begin{array}{llll}
\text { \# Cevab-1 } & \text { soru-yu } & \text { duy-ma-mışcasına } & \text { yanlış-t1. } \\
\text { answer-POSS-3SG } & \text { question-ACC } & \text { hear-NEG-HCM } & \text { wrong-PST } \\
\text { Lit: 'His answer was wrong as if he did not hear the question.' }
\end{array}
$$

We leave it to future work to address the issue of speaker variability and determine whether the ambiguity under discussion is an inter-speaker phenomenon or may reside in a single grammar. The former possibility suggests that Turkish speakers have not converged on the same meaning for-MIŞCASINA while the latter possibility suggests that -MIŞCASINA may genuinely be ambiguous for some speakers.

7. Concluding Remarks. In this paper, we have provided a targeted investigation of the syntactic and semantic properties of the Turkish hypothetical marker -MIŞCASINA. We have argued that -MIŞCASINA syntactically builds sentential modifiers and semantically functions as a comparative operator that compares an actual degree against hypothetical degrees. We have shown that HCM-clauses are licensed as sentential modifiers in grammatical contexts that make available an element that denotes a gradable property. Our semantics for -MIŞCASINA essentially builds on this peculiar property of HCM-clauses. We have also shown that our account 
correctly rules out HCM-clauses in grammatical contexts where the only available gradable property is used up by another comparative operator.

In addition to the core cases investigated in this paper, we have considered challenging examples which not only resist an analysis in terms of degree-comparison but also do not receive uniform acceptability ratings across speakers. In analogy to parallel data in English, we have pointed out the possibility that for some speakers -MIŞCASINA may in fact be ambiguous. Along with the other issues pointed out in the paper, we leave a large scale investigation of this potential ambiguity to future work.

\section{References}

Bhatt, Rajesh \& Shoichi Takahashi. 2007. Direct comparisons: Resurrecting the direct analysis of phrasal comparatives. In Semantics and linguistic theory, vol. 17, 19-36. http://dx.doi.org/10.3765/salt.v17i0.2958.

Bledin, Justin \& Sadhwi Srinivas. 2019. As ifs. Proceedings of Sinn und Bedeutung 23. http://dx.doi.org/10.18148/sub/2019.v23i1.509.

Brook, Marisa. 2014. Comparative complementizers in Canadian English: I-nsights from early fiction. University of Pennsylvania Working Papers in Linguistics 20(2). 2.

Bücking, Sebastian. 2017. Composing wie wenn-the semantics of hypothetical comparison clauses in German. Natural Language \& Linguistic Theory 35(4). 979-1025. http://dx.doi.org/10.1007/s11049-017-9364-1.

Heim, Irene. 2000. Degree operators and scope. In Semantics and linguistic theory, vol. 10, 40-64. http://dx.doi.org/10.3765/salt.v10i0.3102.

Heim, Irene \& Angelika Kratzer. 1998. Semantics in Generative Grammar. Wiley-Blackwell.

Kennedy, Christopher \& Louise McNally. 2005. Scale structure, degree modification, and the semantics of gradable predicates. Language 81. 345-381. http://dx.doi.org/10.1353/lan.2005.0071.

Keshet, Ezra. 2010. Split intensionality: a new scope theory of de re and de dicto. Linguistics and Philosophy 33(4). 251-283. http://dx.doi.org/10.1007/s10988-011-9081-x.

Kratzer, Angelika. 1981. The Notional Category of Modality. 38-74. De Gruyter. http://dx.doi.org/10.1515/9783110842524-004.

Kratzer, Angelika. 1991. Modality. In A. von Stechow \& D. Wunderlich (eds.), Semantik: Ein internationales Handbuch zeitgenoessischer Forschung. 639-650. Berlin: De Gruyter.

Rett, Jessica. 2020. Separate but Equal: A Typology of Equative Constructions. 163-204. Leiden, The Netherlands: Brill. http://dx.doi.org/10.1163/9789004431515_006.

Schwarzschild, Roger. 2008. The Semantics of Comparatives and Other Degree Constructions. Language and Linguistics Compass 2(2). 308-331. http://dx.doi.org/10.1111/j.1749818X.2007.00049.x. Publisher: John Wiley \& Sons, Ltd.

Stechow, Arnim von. 1984. Comparing Semantic Theories of Comparison. Journal of Semantics 3(1-2). 1-77. http://dx.doi.org/10.1093/jos/3.1-2.1.

Umbach, Carla \& Helmar Gust. 2014. Similarity demonstratives. SI: Modification at the Interfaces 149. 74-93. http://dx.doi.org/10.1016/j.lingua.2014.05.003. 